\title{
Simulation of Performance of Thermal Energy Storage in a Solar Cooker
}

\author{
Vikas Chourasia \\ Mechanical Engineering Department \\ Maulana Azad National Institute of Technology \\ Bhopal (M.P.) India \\ vikaschourasia2@gmail.com
}

\begin{abstract}
Finite element analysis was used to simulate the performance of thermal energy storage in a solar cooker which was fabricated by our team. This cooker stores solar energy in materials like sand for future use. It is inexpensive to construct and can be widely used in villages and urban areas. The cooker energy storage unit consists of a cubical solid block which contains sand as a solar-energy storage unit, along with conducting aluminum sheets for uniform heat distribution throughout the block. The block is enclosed in a uniform layer of insulation, except the cavities on the top surface to allow heating of the sand and as well as near the cooking pot. This heated sand can be used at night to heat a cooking pot which is centrally located in the storage box. A paraboloidal concentrator focuses solar radiation through a secondary reflector onto the central zone of the storage block through the cavity in the insulation. The storage is charged for a set period of time and heat is subsequently discharged to a pot during the night time. The effects on cooker performance are compared for various numbers of plates in the storage block. The temperature attained at various stages is studied for various models. This can be used to cook food in a slow manner and can be kept heated until night.
\end{abstract}

Keywords: Solar cooker; simulation; thermal storage; night solar cooker; ANSYS; transient thermal analysis; slow cooker.

\section{Introduction}

Various types of solar cookers, with or without thermal energy storage, have been developed over the years ${ }^{1}$. The main advantage of using a thermal energy storage unit for a solar cooker is that cooking can be carried out during periods when there is very little or no solar radiation. A solar cooker with thermal energy storage can also be used during peak hours to limit the demand of electrical energy for cooking.

The method of characterizing performance of a solar cooker is based on energy analysis done mathematically and computationally. This analysis is based on energy conservation (first law of thermodynamics) to evaluate available energy and performance of the heat storing solar cooker. The efficiency, or performance, depends upon many factors such as design of solar concentrator (optical efficiency, thermal efficiency), storage material, and the system used to store the energy ${ }^{2}$. 


\section{Design of the Parabolic Reflector}

Compound parabolic concentrators (CPCs) are a class of concentrators that consist of rotated parabolic sections which have a concentration factor for planar receivers, which is the thermodynamic limit: $1 / \sin (\theta / 2)$ where $\theta$ is the angle within which reflectors direct the entire light incident onto aperture and down to the receiver (Fig.1).

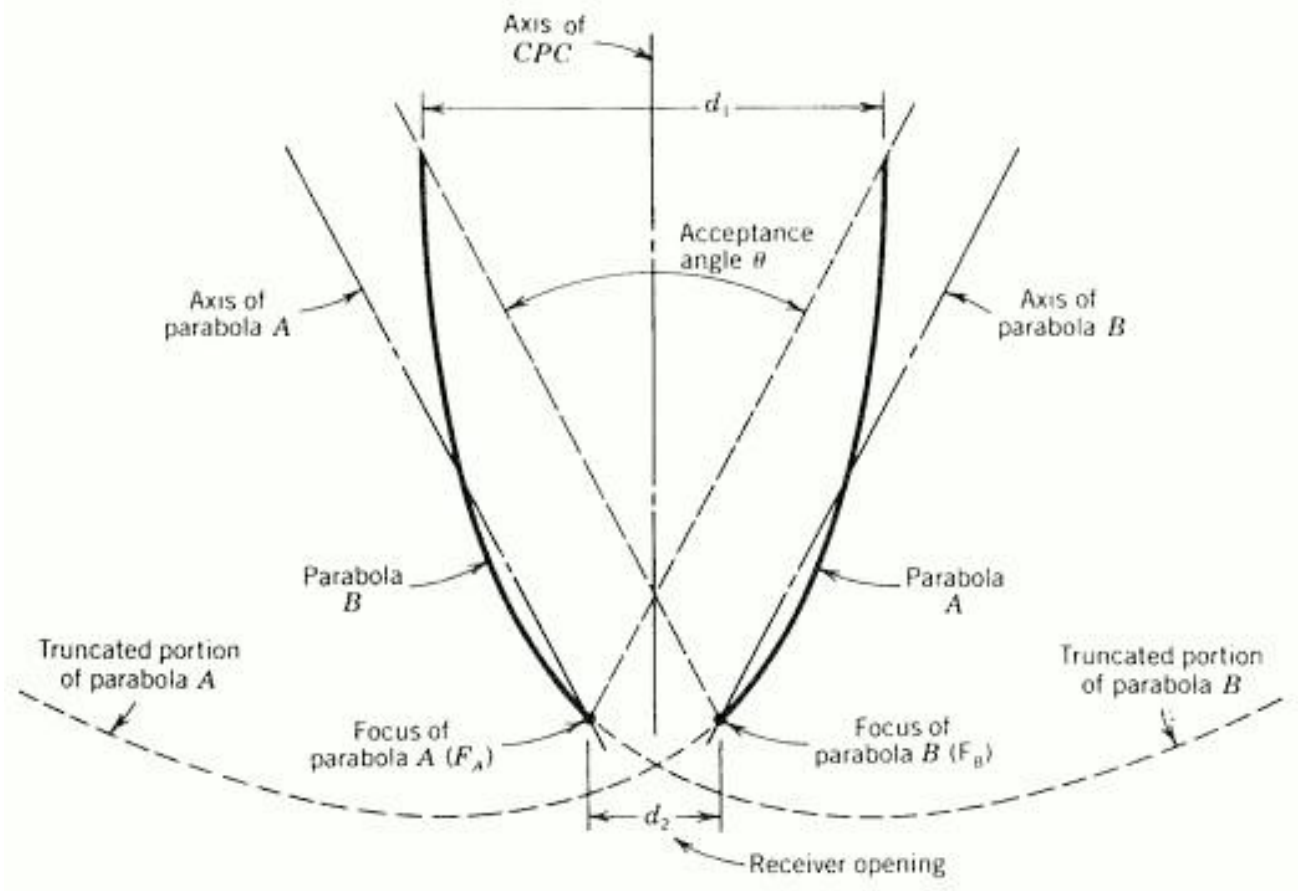

FIGURE 1

THE COMPOUND PARABOLIC CONCENTRATOR (CPC)

The area of concentrator in terms of area of aperture is given by equation [1].

$$
A_{\text {con }}=A_{a}(1+\sin \theta)\left[\frac{\cos \theta}{\sin ^{2} \theta}+\ln \left\{\frac{(1+\sin \theta)(1+\cos \theta)}{\sin \theta\{\cos \theta+\sqrt[2]{(2+2 \sin \theta)}\}}\right\}-\frac{\sqrt{2} \cos \theta}{(1+\sin \theta)}\right]
$$

From the relation given by $\mathrm{Rabl}^{3}$, we determine the average number of reflections, $\mathrm{m}$, passing through a CPC inside its acceptance angle, given by equation [2]

$$
m=\frac{1}{2 \sin \theta}\left(\frac{A_{\operatorname{con}}}{A_{a}}\right)-\frac{(1+2 \sin \theta)(1-\sin \theta)}{2 \sin \theta^{2}}
$$

The effective emissivity of CPC, $\tau_{\mathrm{cpc}}$ which accounts for reflection loss inside the CPC depends on surface and the average number of reflections $(\mathrm{m})$ and is given by equation [3]

$$
\tau_{c p c}=\rho^{m}
$$

The insolation within the acceptance angle of $\mathrm{CPC}$ with concentration ratio $\mathrm{C}$, is given by equation [4]

$$
I_{c p c}=I_{t}-\left(1-\frac{1}{c}\right) I_{d}
$$


Where $I_{t}$ and $I_{d}$ are the total and diffuse radiation respectively on aperture plane.

The absorbed radiation $I_{a}$ in terms of $I_{c p c}$ is given by equation [5]

$$
I_{a}=I_{c p c} \tau_{c o v e r} \tau_{c p c} \alpha_{r} \gamma
$$

Where:

$\tau_{\text {cover }}=$ transmissivity of cover

$\tau_{c p c}=$ effective transmissivity of $C P C$

$\alpha_{r}=$ absorptivity of receiver

$$
\gamma=\text { correction factor for diffuse radiation }=1-\left(1-\frac{1}{c}\right) \frac{\mathrm{Ia}}{\mathrm{It}}
$$

By taking suitable values for the acceptance angle, we calculate the average solar radiation incident on the absorber i.e. sand, through the glass cover filled with air having transmittance value of about 0.9 . This will be used as the solar input for the solar cooker box considered for the simulation.

\section{Thermal Energy Storage and Cooking system}

Conceptual diagrams of the thermal energy storage system and the solar cooker are shown in Fig 2, in which a cylindrical parabolic mirror concentrates the solar radiation on a second Vshaped mirror. This mirror reflects the light down through insulated glass to an absorber plate in the storage unit. The storage unit consists of sand and aluminum plates inserted in sand so as to maximize the conduction throughout the unit. Sand was chosen as the thermal storage material because of its high specific heat capacity and its low thermal conductivity.
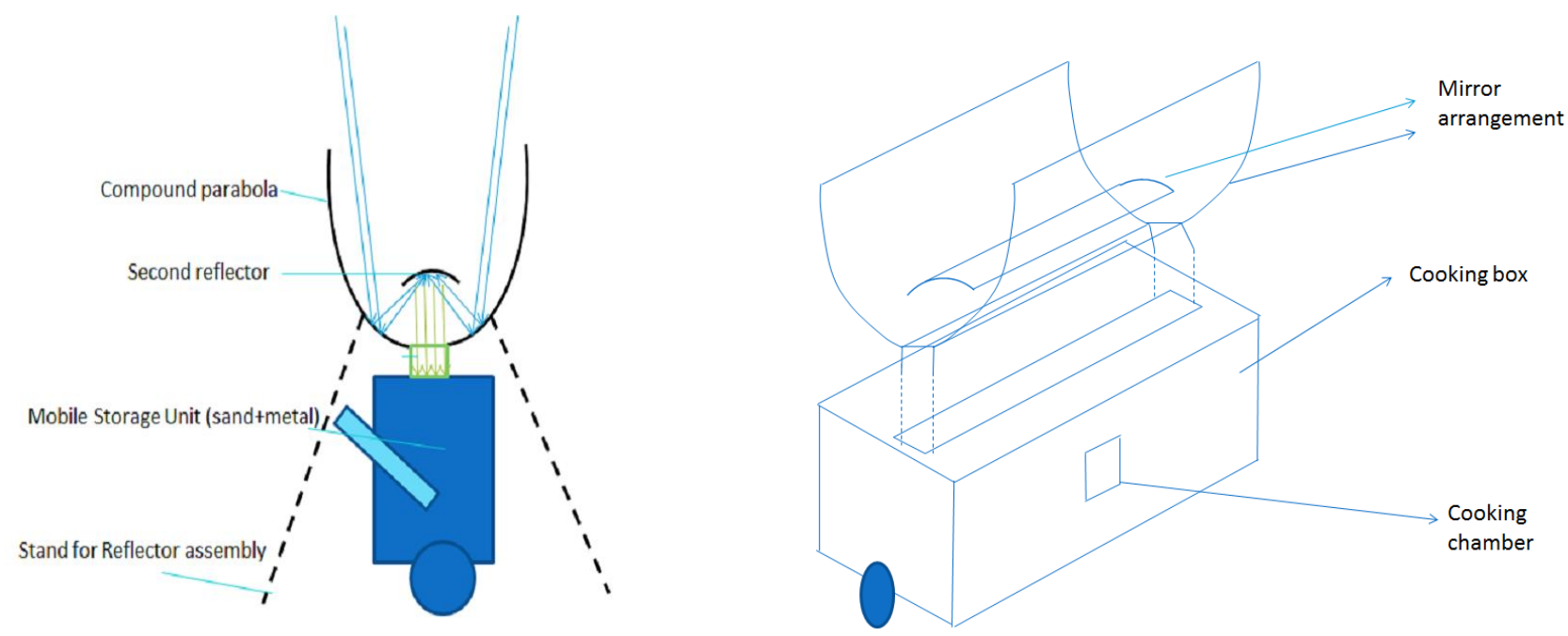

FIGURE 2

SKETCH DIAGRAM OF SOLAR COOKER 
Sand is easily available and not very expensive. The model consists of two boxes, one inner and other outer, in which inner box is held. The inner box is designed to hold cooking material which uses the energy from the absorber plate to cook. The outer box is designed to hold insulating material so as to minimize heat transfer from the box to the atmosphere.

For uniform distribution of heat throughout the sand, aluminum plates are used, as aluminum has good conductivity. The spacing between the aluminum plates was such that we distributed heat in the box to the maximum so that after discharging we were left with much needed temperature at larger area of the box. If the space between two plates was much less, then we would have higher temperatures during the charging phase, and during discharging we would not obtain higher temperatures in the larger area of the box. If the space was large, we would have greater distribution of heat in the box but the maximum attainable temperature would be less after discharging. Hence there was a trade-off between the two strategies.

We considered three models for analysis. A $10 \mathrm{~mm}$ aluminum plate was placed at the center for direct distribution of heat to the cooking pot in all the models. Then for the first model we had two plates of $10 \mathrm{~mm}$ on each side, at a distance of $80 \mathrm{~mm}$ from the center plate. These plates have a gap of $10 \mathrm{~mm}$ between them. For the second model there was one plate of $10 \mathrm{~mm}$ thickness on each side at a distance of $40 \mathrm{~mm}$ from the two plates of previous model. Similarly for third model we again had $10 \mathrm{~mm}$ thick plate at $40 \mathrm{~mm}$ distance on each side from previous plate

Heat transfer through the plates at any depth was determined using a simple conduction equation in which the quantity of heat (dQ), passing through a surface having surface area $(\mathrm{dA})$, per time interval $(\mathrm{dt})$ is proportional to the temperature gradient $\left(\frac{\delta T}{\delta n}\right)$ and mathematically can be expressed as

$$
d Q=-K \frac{\delta T}{\delta n} d A d t
$$

The proportionality factor $\mathrm{K}$ in equation is the physical property of the substance called the thermal conductivity.

\section{Simulation of Storage System}

A methodology to generate the design space of the system considering simultaneous variations of different input parameters was undertaken. Input parameters included solar radiation data, desired solar fraction, collector characteristics, storage parameters, and surrounding conditions. The data for average solar radiation input for April month was taken from MNRE Indian Metrological Department ${ }^{4}$. Taking the suitable collector areas and optical efficiency of parabolic reflector about 0.90 , the average solar flux of $250 \mathrm{w} / \mathrm{m}^{2}-300$ $\mathrm{w} / \mathrm{m}^{2}$ was determined. This was the basis of our design data which is similar to reference the paper $^{5,6}$. Simulation modelling was done for various models having different numbers of aluminum plates for the heat distribution in the sand. In all the models transient analysis was done.

Simulation was based on four time steps; first, three time steps have total heat input of 8 hours in which there are time steps of three, three and two hours. During first time step, the heat input increased from 250 watts to 300 watts, then remained constant for three hours, and then decreased for the last two hour to 250 watts as shown in Figure 3. In final time step transient analysis of heat loss in surrounding is done for 2 hours with heat input deactivated. In model ambient temperature is $30^{\circ} \mathrm{C}$.

Heat input is given to the top surface of the aluminum for the above specified timings. This plate is $150 \mathrm{~mm}$ wide and $1 \mathrm{~m}$ long. Complete outer surface of the box is considered to have convection as boundary condition with convective film coefficient of $5 \mathrm{~W} / \mathrm{m} 2{ }^{\circ} \mathrm{C}$ during the complete period of simulation. Both the aluminum and sand have contact with each other for 
heat transfer. The basic three dimensional model is shown below in Figure 3. The box has a dimension of $1 \mathrm{~m} \times 0.4 \mathrm{~m} \times 0.4 \mathrm{~m}$ with a total mass of sand nearly $200 \mathrm{~kg}$.

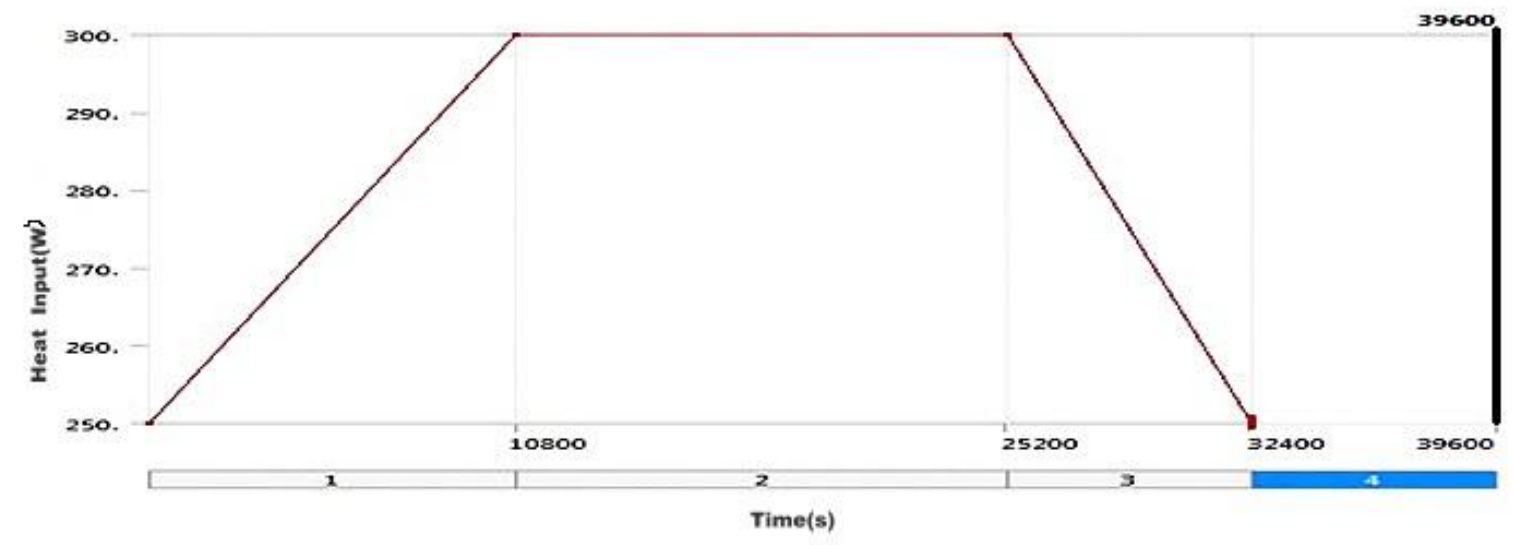

FIGURE 3

HEAT INPUT VARIATION

\section{Discussion and Results}

There are three models with the same dimensions but a varying number of aluminum plates:

- Model 1: Two plates

- Model 2: Three plates

- Model 3: Four plates.

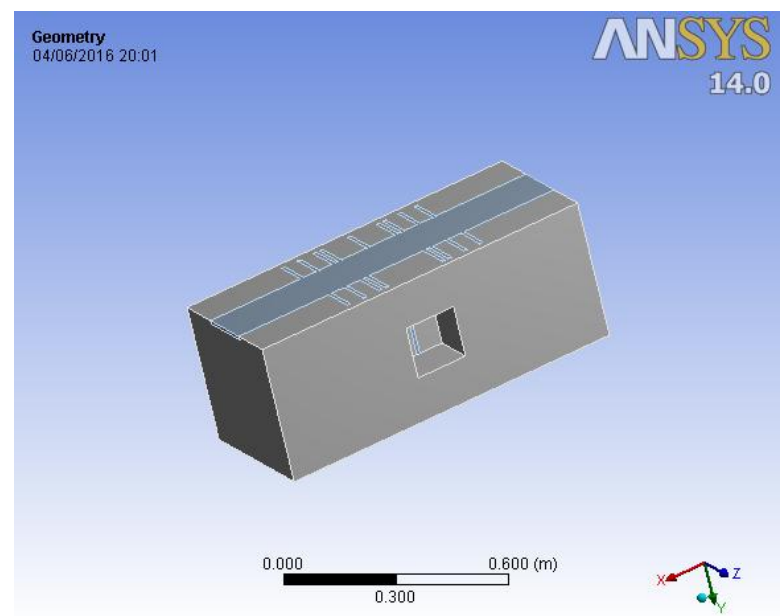

FIGURE 4

THREE DIMENSIONAL MODEL

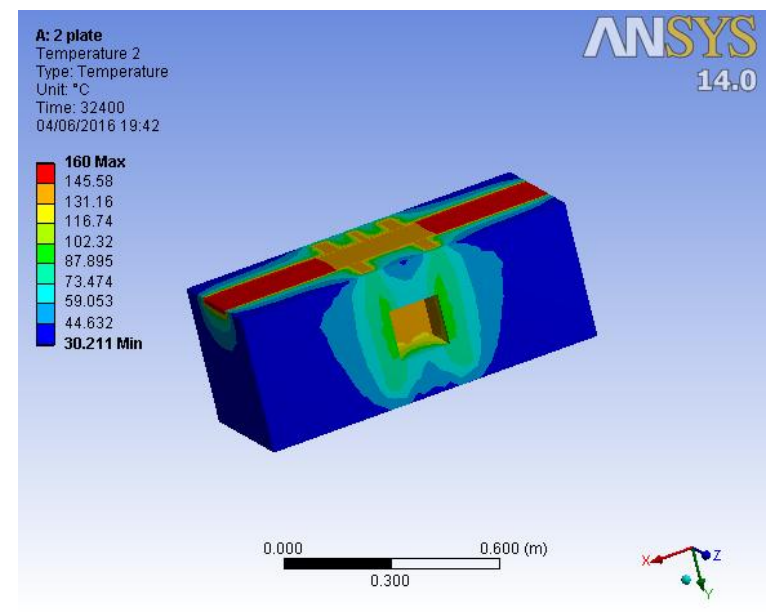

FIGURE 5

DISTRIBUTION OF TEMPERATURE IN BLOCK WITH TWO PLATES AFTER CHARGING 


\section{Model 1}

With two aluminum plates, the heat input is given as shown and the analysis is done. For the given model, the contours of overall temperature distribution after charging is shown in Figure 5. It is clear that the heat transfer in interior of block is mainly because of aluminum plates. The maximum temperature rise is of $160{ }^{\circ} \mathrm{C}$ at the upper surface after 8 hours, although the maximum rise is nearly $171^{\circ} \mathrm{C}$. In the next figure (Figure 6), cut section model is showing temperature distribution near the pot after charging of 8 hours.

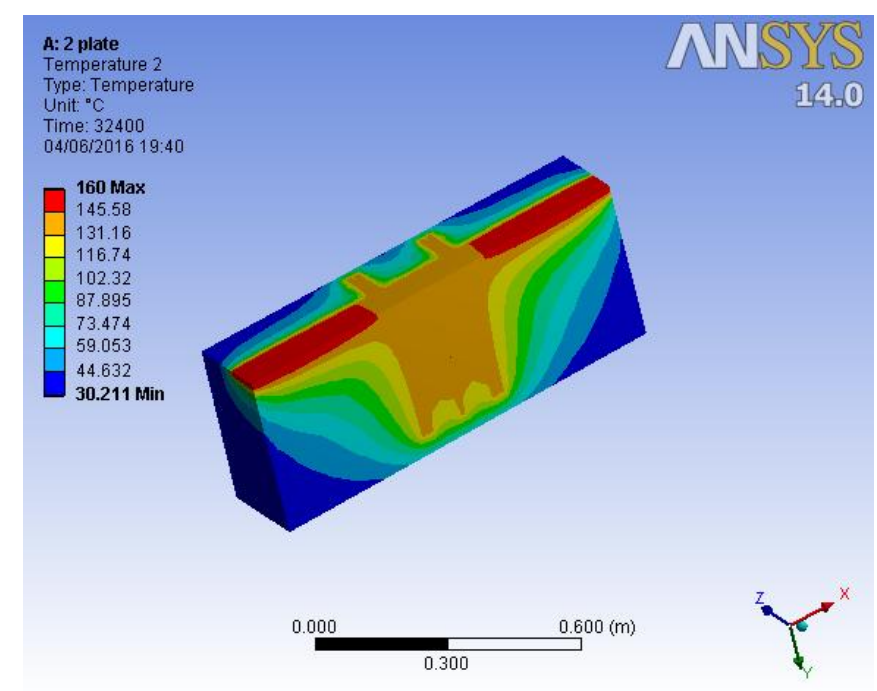

FIGURE 6

CUT SECTION MODEL WITH TWO PLATES SHOWING TEMPERATURE WITHIN POT

After charging for 8 hours the heat input to model is reduced to zero and the model is set for convective heat loss to surrounding. The contours of temperature distribution after discharging are shown in Figures 7 and 8.

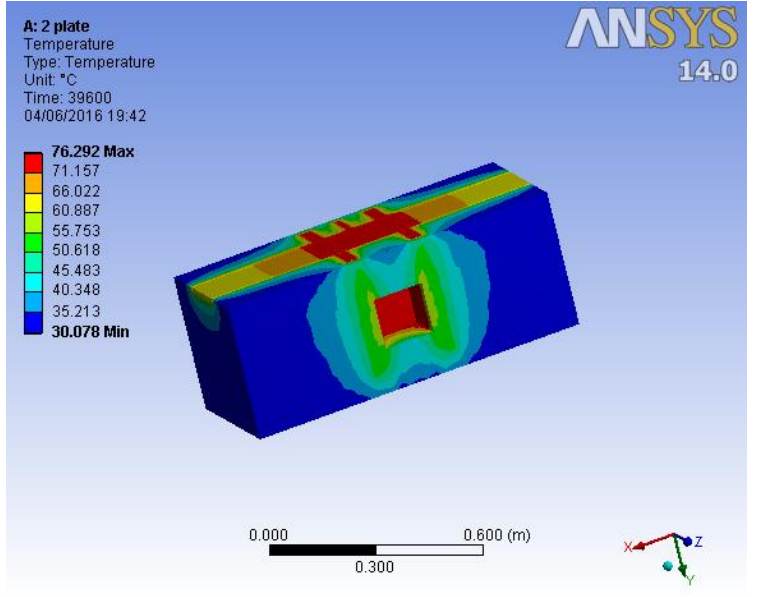

Figure 7

Contours of temperature after discharging (2 plates)

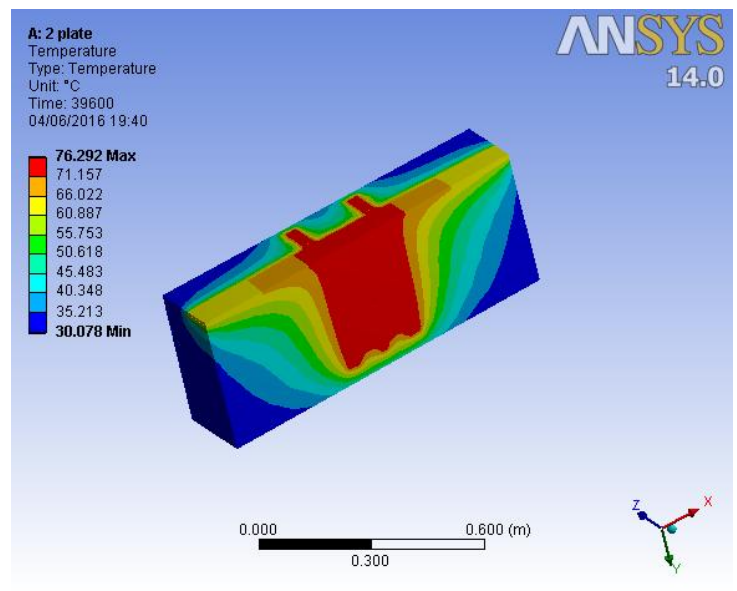

Figure 8

Contours of temperature near pot after discharging ( 2 plates) 
From Figure 7 it is clear that after discharging the temperature at top location near the center is $76{ }^{\circ} \mathrm{C}$. In the next figure, a cut section model is shown, illustrating temperature contours near the pot after discharging with temperature as high as $76{ }^{\circ} \mathrm{C}$ near the pot (Figure 8).

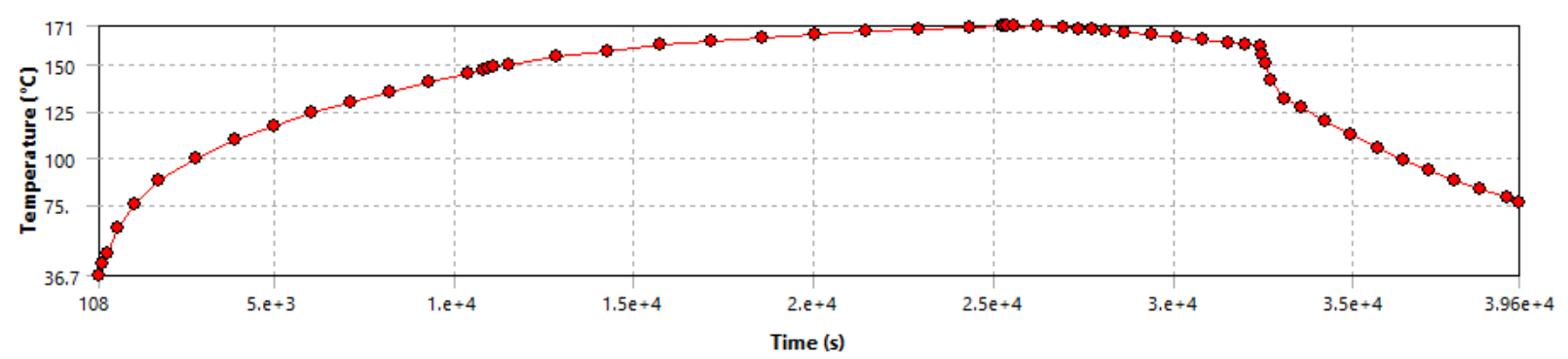

FIGURE 9

RISE AND FALL OF MAXIMUM GLOBAL TEMPERATURE FOR FIRST MODEL

The maximum temperature variation during charging \& discharging are shown below in Figure 9. From the graph it is clear that during charging period temperature inside the storage unit gradually increases and then there is a sudden decrease when the heat input is removed.

\section{Model 2}

In second analysis, our model consists of three aluminum plates inserted within sand box. Again the charging is same, for total eight hours and distribution of heat input is shown in Figures 10 and 11.

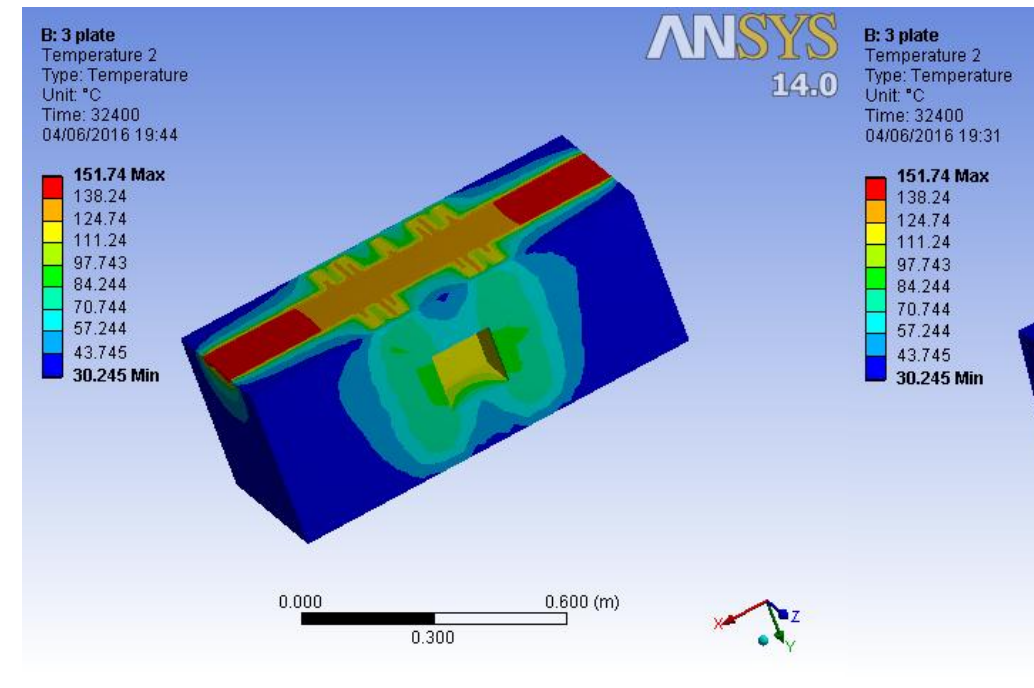

Figure 10

Temperature Distribution in sand box after charging (3 plates)
Temperature distribution near pot after charging (3 plates) 


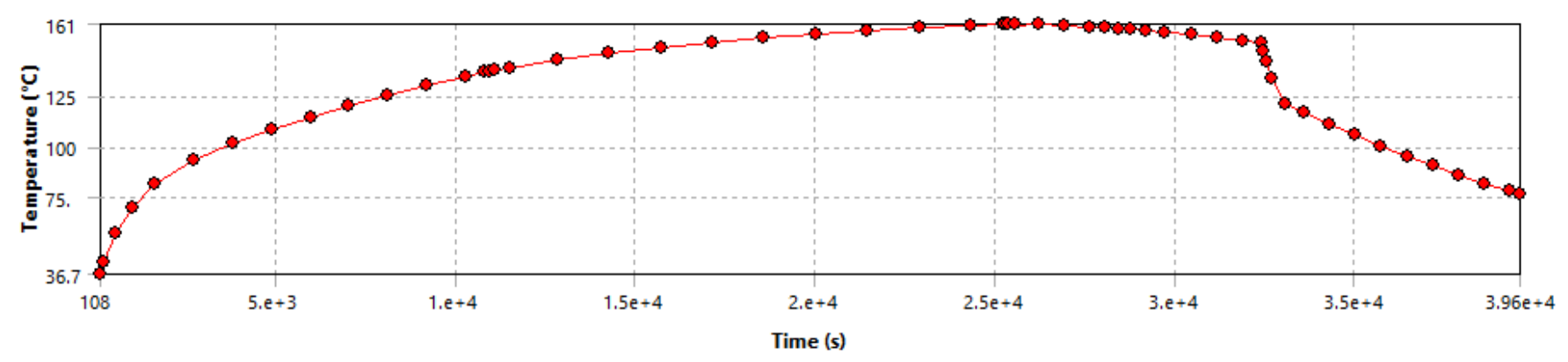

FIGURE 12

RISE AND FALL OF MAXIMUM GLOBAL TEMPERATURE FOR SECOND MODEL

Here we can see that the high temperature rise after the charging has decreased from $171{ }^{\circ} \mathrm{C}$ to $161{ }^{\circ} \mathrm{C}$ due to uniform heating. The decrease in temperatures after the charging process of eight hours is because of the increase in the number of aluminum plates which has dissipated the heat uniformly inside the pot.

In Figures 13 and 14 temperature distributions after discharging of 2 hours are shown with respect to time. When the heat input is reduced to zero, the same decreasing trend of temperature is obtained while discharging. We again have the similar uniform discharging but the temperature loss has not decreased significantly. It is still around the $76{ }^{\circ} \mathrm{C}$. Increase in plate has resulted in uniform distribution as well as low highest temperature and we have more amount of heat distributed in the larger area.

From Figure 12 it is clear that the temperature rise is of $151^{\circ} \mathrm{C}$ after the charging of 8 hours which is also about $10^{\circ} \mathrm{C}$ less than the previous model. Now the temperature rise within the pot is shown in figure 12 . This temperature is also around $76{ }^{\circ} \mathrm{C}$.

The global highest rise and fall of temperature in sand box after charging and discharging are shown in Figure 12.

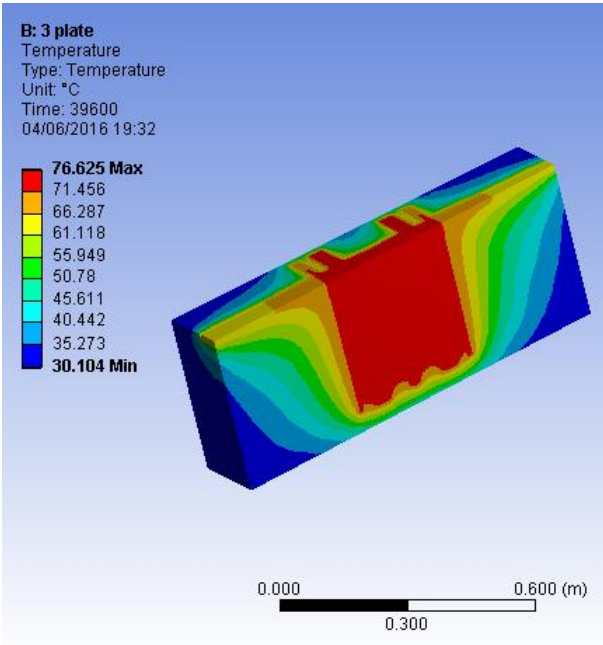

Figure 13

Temperature distribution near pot after discharging (3 plates)
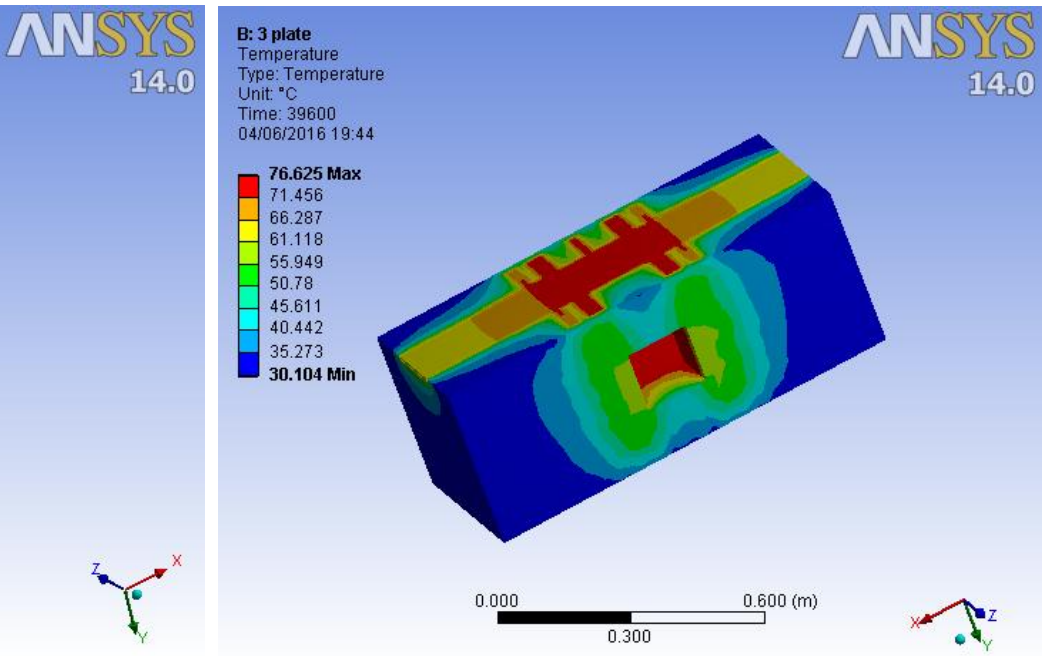

Figure 14

Overall Temperature distribution after discharging (3 plates) 


\section{Model 3}

In the third model all the input conditions are same except that now four aluminum plates are inserted within the sand box. Contours of temperature in overall sand box and in cut section near pot after charging are given below in Figure 15 and 16 respectively.

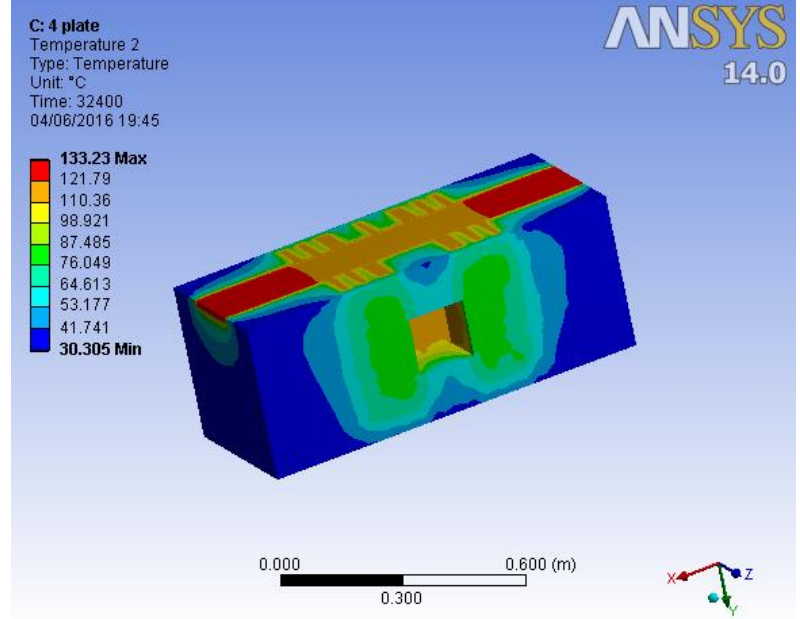

Figure 15

Overall temperature distribution in sand box (4 plates)

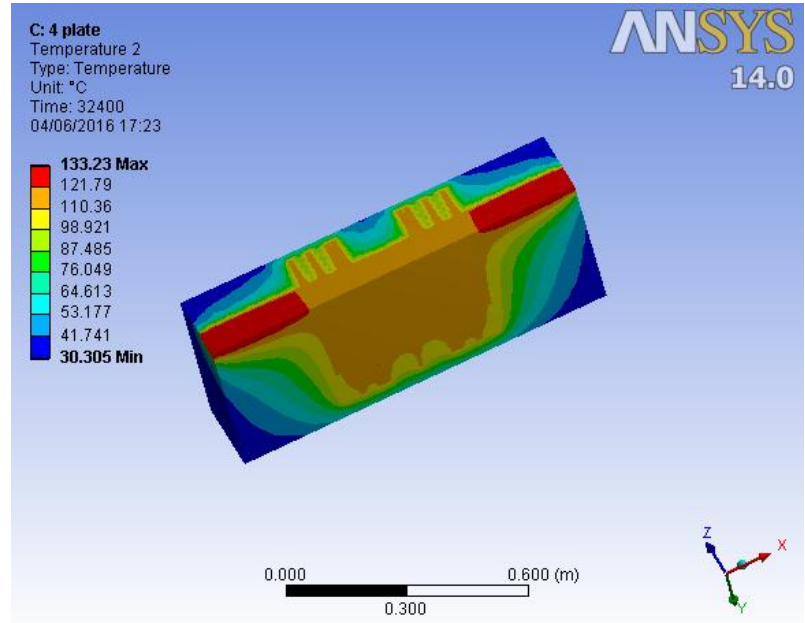

Figure 16

Temperature distribution near pot in cut section (4 plates)

Now after charging heat input is reduced to zero and the model is left to discharge for two hours as previously explained. Contours of temperature after discharging in overall sand box and near pot in cut section model are given below in Figure 17 and 18 respectively.

The temperature after charging has drastically decreased from $151^{\circ} \mathrm{C}$ to $133^{\circ} \mathrm{C}$. We have the same trend for the temperature after discharging which has decreased to $74^{\circ} \mathrm{C}$ from the previous value of $76^{\circ} \mathrm{C}$.

These figures illustrate the fact that though the heat is uniformly distributed but the temperature rise after discharging has also decreased which is not desirable for the cooking process. The overall global maximum rise and fall in Figure 19 also prove this point. 


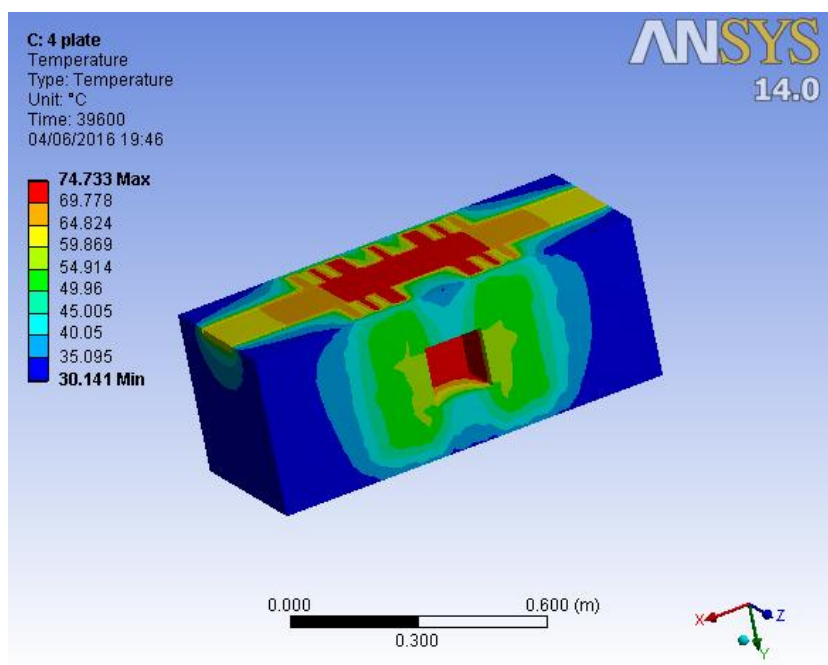

Figure 17

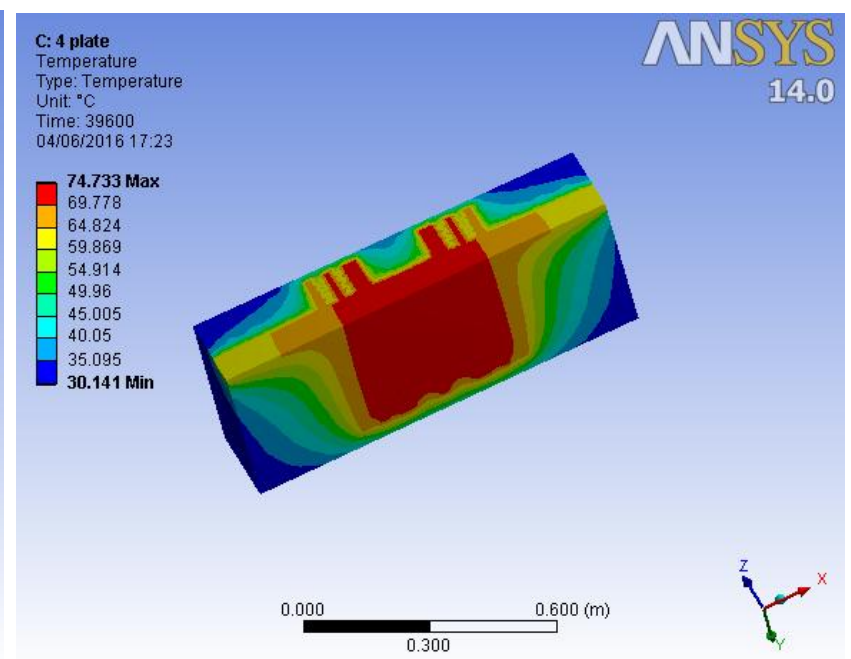

Figure 18

Temperature distribution near pot in cut section (4 plates)

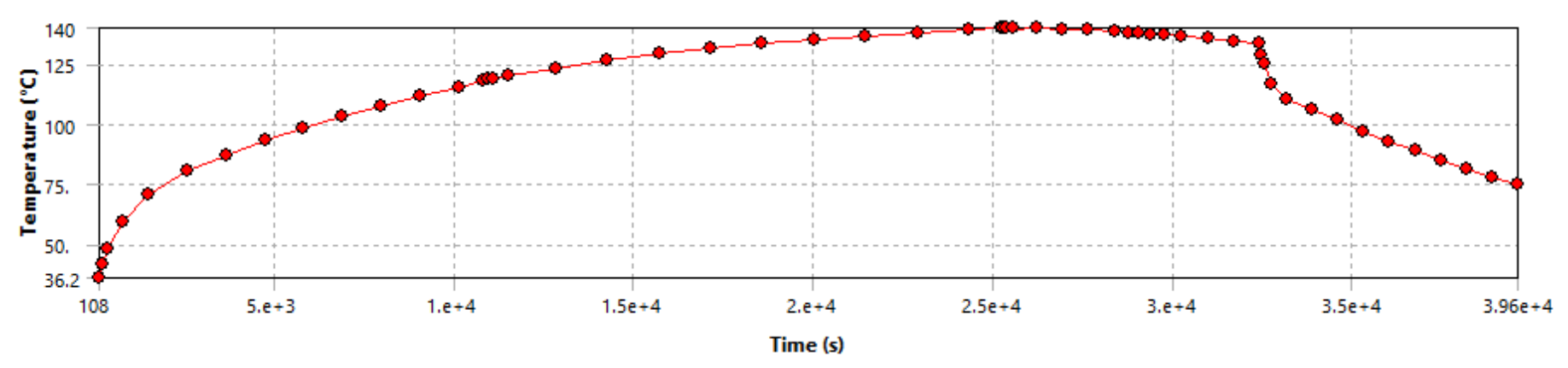

FIGURE 19

RISE AND FALL OF MAXIMUM GLOBAL TEMP FOR THIRD MODEL

\section{Data}

TABLE 1

PROPERTIES OF SAND \& ALUMINUM

\begin{tabular}{|c|c|c|c|}
\hline Density of aluminium & $2770 \mathrm{~kg} \mathrm{~m}^{-3}$ & Density of sand & $1281 \mathrm{~kg} \mathrm{~m}^{-3}$ \\
\hline $\begin{array}{c}\text { Coefficient of Thermal } \\
\text { Expansion (aluminum) }\end{array}$ & $2.3 \mathrm{e}-005 \mathrm{C}^{-1}$ & Specific Heat (sand) & $0.835 \mathrm{~J} \mathrm{~g}^{-1} \mathrm{~K}^{-1}$ \\
\hline Specific Heat of aluminium & $875 \mathrm{~J} \mathrm{~kg}^{-1} \mathrm{C}^{-1}$ & $\begin{array}{c}\text { Thermal } \\
\text { Conductivity(sand) }\end{array}$ & $0.2 \mathrm{~W} \mathrm{~m}^{-1} \mathrm{~K}^{-1}$ \\
\hline
\end{tabular}

The aluminum data is from ANSYS engineering data ${ }^{6}$ and sand data is from data book of Domkundwar for thermal engineering properties ${ }^{7}$. 


\section{Conclusion}

Different models of thermal energy storage systems and thermal energy utilization are used to perform charging and discharging simulations in solar cooker. The models of thermal energy storage systems are validated with computational results. The results show a greater decrease in temperature value after charging due to uniform distribution as the number of plates is increased but up to a certain number of plates only, then the highest temperature after discharging also decreases. If a higher temperature rise in sand could be attained, then the temperature could be sustained for a longer period of time as the temperature loss is nearly $45^{\circ} \mathrm{C}$ for two hours (or we can say three hours as maximum temperature is attained at seventh hour and not at eighth hour of charging). We also experimented with the thickness and the spacing of the plates. With increasing insulations in sand storage system the overall temperature loss in system can also be reduced. If the concentrator design is improved we can obtain a higher rise in temperature and as we are using sand it can be sustained for a longer time. We can also use a number of concentrators to charge up the same model for higher temperature. Here we have seen that we are nearly getting $76^{\circ} \mathrm{C}$ temperature for the sand box for at least 5-6 hours which can be used as slow cooker ${ }^{8}$ for cooking. Thus we can start cooking food when the temperature is high around $150^{\circ} \mathrm{C}$ and then keep the food warm with temperature around $75^{\circ} \mathrm{C}$. We can also charge the pot using aluminum and then remove it from sand and store the heat energy to be used afterwards.

\section{Nomenclature}

\begin{tabular}{|c|c|c|c|}
\hline $\mathrm{A}_{\mathrm{con}}$ & Area of concentrator & $\mathrm{A}_{\mathrm{a}}$ & Area of aperture \\
\hline$\theta$ & Acceptance Angle & $\tau_{\mathrm{cpc}}$ & $\begin{array}{c}\text { Effective emissivity } \\
\text { of CPC }\end{array}$ \\
\hline$\rho$ & Specular reflectivity & $\mathrm{I}_{\mathrm{t}}$ & Total radiation \\
\hline $\mathrm{I}_{\mathrm{d}}$ & Diffused Radiation & $\mathrm{C}$ & Concentration ratio \\
\hline$\gamma$ & Correction factor & $\alpha_{\mathrm{r}}$ & $\begin{array}{c}\text { Absorptivity of } \\
\text { receiver }\end{array}$ \\
\hline $\mathrm{K}$ & Thermal conductivity & $\mathrm{m}$ & $\begin{array}{c}\text { Number of } \\
\text { reflections }\end{array}$ \\
\hline
\end{tabular}

\section{ACKNOWLEDGEMENTS}

I acknowledge the guidance given by Prof. Rajesh Gupta, Prof. A. Rehman and Prof K. R. Aharwal of mechanical engineering department of Maulana Azad National Institute of Technology. We would also like to acknowledge the funding done by our college for our Night Solar Cooker. 


\section{REFERENCES}

1. R.M. Muthusivagami, R. Velraj, R. Sethumadhavan, Solar cookers with and without thermal storage-A review, Renewable and Sustainable Energy Reviews Volume 14, Issue 2, (February 2010) 691-701

2. D.Haillot, V.Goetz, X.Py, M.Benabdelkarim, High performance storage composite for the enhancement of solar domestic hot water systems, Solar Energy 85(2011) 1021-1027.

3. H.P. Garg and J Prakash solar energy fundamentals and applications.

4. Solar radiation handbook 2008 MNRE Indian Metrological department.

5. A Mawire, M.Mcpherson, R.R.J. van den Heetkamp, solar energy material and cells 92 (2008) 1668-1676.

5. A Mawire, M.Mcpherson, R.R.J. van den Heetkamp discharging simulations of a thermal energy storage system for an indirect solar cooker.

6. ANSYS engineering data of ANSYS 14.0.

7. Data book of Thermal engineering by Domkundwar.

8. Temperature of slow cooker discussed at http://chowhound.chow.com/topics/725139

9. ANSYS 14.0 User guide. 